\title{
Study on optimum technological conditions for producing androstenedione by microbial method
}

\author{
Haishan SHI ${ }^{123}$, Ying YANG ${ }^{12}$, Weihua LI $^{12}$ Hui ZHANG ${ }^{123}$ and Xiaolei CHENG ${ }^{123}$ \\ ${ }^{1}$ College of Environmental and Energy Engineering, Anhui Jianzhu University,230000 Hefei, Anhui, China \\ ${ }^{2}$ Key Laboratory of Anhui Province of Water Pollution Control and Wastewater Reuse, Anhui Jianzhu University, 23000 Hefei, Anhui, \\ China \\ ${ }^{3}$ Key Laboratory of Huizhou Architecture in Anhui Province, Anhui Jianzhu University, 23000 Hefei, Anhui, China
}

\begin{abstract}
As an indispensable intermediate, androstenedione is widely used in drug manufacturing, especially steroidal drugs. However, the chemical manufacturing process of androstenedione is generally complicated and difficult, and it will cause serious environmental pollution in the production process. The biological method for the production of androstenedione has a very promising development prospect, because it is more economical and environmentally friendly than chemical methods. In order to better produce androstenedione on a large scale, the imbalance between supply and demand can be solved. In this study, the biaqueous phase system was used to increase the substrate concentration, and the method of transforming plant sterol by mycobacterium was used to produce androstenedione. The optimal conditions for the production of androstenedione by microbial assay were determined by orthogonal test: the aqueous two-phase system was water/ sunflower oil, the temperature was $30^{\circ} \mathrm{C}$, the initial $\mathrm{pH}$ was 6.5 , the substrate concentration was $0.4 \mathrm{~g} / \mathrm{L}$, the rotation speed was $250 \mathrm{rpm}$, and the inoculation was carried out. The amount was $14.83 \%$, the organic ratio was $20.65 \%$, and the liquid loading was $150 / 500 \mathrm{~mL}$. The preliminary production of androstenedione by microbial method has found suitable process conditions and provided data and theoretical support for its large-scale production.
\end{abstract}

\section{Introduction}

Anthraquinone is a widely used drug. According to statistics, there are more than 150 steroids currently used for clinical treatment ${ }^{[1]}$. Terpenoids generally contain a steroidal nucleus, which is the reason for its special structure ${ }^{[2]}$.In recent years, due to the continuous development of medicine, the demand for steroids has surged $^{[3]}$, natural extraction methods have been unable to meet market demand, and artificial synthesis has become new access to steroids. Androstenedione (AD) is an essential intermediate for the synthesis of most steroids in this context ${ }^{[4]}$. It is produced by the traditional method of extracting diosgenin from the resources of the genus dioscorea ${ }^{[5]}$ and then further synthesizing it by chemical methods.

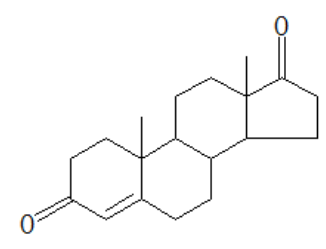

Fig.1 Structure of androstenedione
However, this method of natural extraction plus chemical synthesis requires harsh reaction conditions and generally requires the use of a special catalyst ${ }^{[6]}$. And the steps are numerous, the synthesis is difficult, the unit price is even higher up to 1000 yuan $/ \mathrm{kg}^{[7]}$.

It is subject to other natural factors such as weather, seasons and geography because of the growth cycle of natural raw materials ${ }^{[8]}$. A variety of harmful substances such as organic strong acids and heavy metals are present in the waste liquid produced in the process of synthesizing $\mathrm{AD}$ by this method ${ }^{[9]}$, it is not only difficult to deal with the waste liquid, but also causes unrecoverable pollution to the water environment and soil environment ${ }^{[10]}$.

With the continuous development of biological downstream technology, microbial transformation has become a new way to obtain AD. AD with good dispersibility and stability can be produced by the degradation of phytosterols ${ }^{[11]}$ by many bacteria, such as Nocardia, Arthrobacter and Mycobacterium [12]. The microbial transformation method has the advantages of simple steps, low cost, mild reaction conditions, and less subject factors, compared with the traditional natural extraction and chemical synthesis methods. Moreover, the remaining fermentation broth still has the value of being reused after the $\mathrm{AD}$ in the culture solution is extracted ${ }^{[13]}$, The recovered oil meets the national secondary oil standard after refining, and can be used as a raw material 
for biodiesel or recycled in the factory. In addition, it is also possible to recover a highly purified protein that can be recycled from the mash of the extracted oil by leaching.

Phytosterols are cheap and easy to obtain as a substrate, but it is difficult to dissolve in water ${ }^{[14]}$. In order to bring the mycobacteria into full contact with the substrate, an oil/water two-phase system was constructed to increase the substrate concentration ${ }^{[15]}$, thereby increasing the yield. In addition to the type of oil phase, fermentation temperature [16], initial $\mathrm{pH}$, and substrate concentration are all factors that affect AD yield. The purpose of this study was to find out the optimal conditions for the production of $\mathrm{AD}$ by microbial transformation, and to provide a technical reference for the large-scale production of $\mathrm{AD}$ plants.

\section{Materials and methods}

\subsection{Materials}

\subsubsection{Bacterial surce}

Mycobacterium sp. BD-696, College of Food and Biological Engineering, Hefei University of Technology.

\subsubsection{Reagents and instruments}

Main reagents: Phytosterol, Sinopharm Chemical Reagent Co., Ltd. Androstenedione, Sinopharm Chemical Reagent Co., Ltd. Ethyl acetate, Shanghai Maclean Biochemical Technology Co., Ltd. Methanol, Sinopharm Chemical Reagent Co., Ltd. And n-hexane, Shanghai Zhongqin Chemical Reagent Co., Ltd.

Main instruments: vertical pressure steam sterilizer yxq-100sii, medical equipment factory of Shanghai boxun industrial Co., Ltd. Bs-1e constant temperature oscillating table, jintan chengxi fuwei experimental instrument factory. Medical refrigerator hyc-260, Qingdao haier special electric appliance Co., Ltd. Tgl-15b, high-speed table centrifuge, Shanghai 1.2.2 Solid Culture Method

Culture medium formula: beef extract $0.3 \%$, peptone $1.0 \%, \mathrm{NaCl} 0.5 \%$, agar $1.5-2.0 \%$; $\mathrm{pH} 7.0-7.2$.

Cultural method: the strains were purified by plate scribing and dilution to obtain a single colony, and cultured at $30^{\circ} \mathrm{C}$ in a constant temperature incubator for observation and reserve ${ }^{[19]}$.

\subsubsection{Seed Culture Method}

Culture medium formula: beef extract $0.68 \%$, molasses $5.4 \%$, glucose $0.6 \%$, potassium dihydrogen phosphate $0.1 \%$, GPE $0.007 \%$, pH 8.3-8.5 $5^{[20]}$.

Cultural method: the purified single colonies were picked from the solid medium using an inoculating loop, inoculated into a liquid medium, and cultured in a constant temperature oscillating shaking table at $30^{\circ} \mathrm{C}$ and 120 $\mathrm{r} / \mathrm{min}$ for 3 days.

\subsubsection{Fermentation culture method}

Culture medium formula: beef extract $0.68 \%$, oil $15 \%$, molasses $5.4 \%$, glucose $0.6 \%$, potassium dihydrogen phosphate $0.1 \%$, GPE $0.007 \%$. Temperature, $\mathrm{pH}$, and substrate (phytosterol) concentration were variables.

Cultural method: A certain volume of the bacterial liquid was aspirated from the liquid seed culture solution in the fermentation broth, and fermented for 7 days in a constant temperature shaker at $160 \mathrm{r} / \mathrm{min}^{[21]}$.

\subsubsection{Research methods for strain growth}

Samples of the bacterial solution taken every 6 hours during the seed culture process, diluted $10^{5}$ times with pure water, and use an ultraviolet spectrophotometer to measure the absorbance of the diluted bacterial anting scientific instrument factory. Agilent high performance liquid chromatograph 1-3000, Beijing puyuan jingdian technology Co., Ltd. Dhg-9030a, Shanghai sanfa scientific instrument Co., Ltd. Shp-250fe, Shanghai sanfa scientific instrument Co., Ltd. Uv-spectrophotometer evolution300/600, Thermo Fisher Scientific-Shanghai.

\subsection{Methods}

\subsubsection{Orthogonal experiment method}

Using the orthogonal test method ${ }^{[17]}$, the $\mathrm{pH}$ and temperature of the aqueous two-phase fermentation system, the concentration of the substrate (phytosterol), and the type of vegetable oil are used as variables. The correspondence between the types of organic phases and numbers is shown in Table 1. And the orthogonal test was designed by SPSS and its results are shown in Table 3.

After the optimal $\mathrm{pH}$, temperature and substrate concentration are determined [17], the four factors of shaking speed (A), inoculum (B), organic phase (C) and liquid loading (D) were selected for response surface analysis ${ }^{[18]}$ to more comprehensively determine the best microbial production of AD. Process conditions. The values of each factor are shown in Table 2. Based on the Design principle of Box-Behnken combination design, 29 test points were designed by Design-Expert 8.0 software. The response surface design and data results are shown in Table 7.

Table 1. Organic species

\begin{tabular}{|c|c|c|c|c|c|}
\hline Number & $\mathbf{1}$ & $\mathbf{2}$ & $\mathbf{3}$ & $\mathbf{4}$ & $\mathbf{5}$ \\
\hline $\begin{array}{c}\text { Vegetable } \\
\text { oil kind }\end{array}$ & $\begin{array}{c}\text { Sunflower } \\
\text { oil }\end{array}$ & $\begin{array}{c}\text { Soybean } \\
\text { oil }\end{array}$ & $\begin{array}{c}\text { Rapeseed } \\
\text { oil }\end{array}$ & Methanol & $\begin{array}{c}\text { Polyethylene } \\
\text { glycol }\end{array}$ \\
\hline
\end{tabular}

\subsubsection{Solid Culture Method}

Culture medium formula: beef extract $0.3 \%$, peptone $1.0 \%$, $\mathrm{NaCl} 0.5 \%$, agar 1.5-2.0\%; $\mathrm{pH}$ 7.0-7.2.

Cultural method: the strains were purified by plate scribing and dilution to obtain a single colony, and cultured at $30^{\circ} \mathrm{C}$ in a constant temperature incubator for 
observation and reserve ${ }^{[19]}$.

\subsubsection{Seed Culture Method}

Culture medium formula: beef extract $0.68 \%$, molasses $5.4 \%$, glucose $0.6 \%$, potassium dihydrogen phosphate $0.1 \%$, GPE $0.007 \%$, $\mathrm{pH} 8.3-8.5^{[20]}$.

Cultural method: the purified single colonies were picked from the solid medium using an inoculating loop, inoculated into a liquid medium, and cultured in a constant temperature oscillating shaking table at $30^{\circ} \mathrm{C}$ and 120 $\mathrm{r} / \mathrm{min}$ for 3 days.

\subsubsection{Fermentation culture method}

Culture medium formula: beef extract $0.68 \%$, oil $15 \%$, molasses $5.4 \%$, glucose $0.6 \%$, potassium dihydrogen phosphate $0.1 \%$, GPE $0.007 \%$. Temperature, $\mathrm{pH}$, and substrate (phytosterol) concentration were variables.

Cultural method: A certain volume of the bacterial liquid was aspirated from the liquid seed culture solution in the fermentation broth, and fermented for 7 days in a constant temperature shaker at $160 \mathrm{r} / \mathrm{min}^{[21]}$.

\subsubsection{Research methods for strain growth}

Samples of the bacterial solution taken every 6 hours during the seed culture process, diluted $10^{5}$ times with pure water, and use an ultraviolet spectrophotometer to measure the absorbance of the diluted bacterial solution at a wavelength of $650 \mathrm{~nm}$. The growth curve of the strain was plotted with the time coordinate as the abscissa and the absorbance as the ordinate to represent the growth of Mycobacteria BD-696.

\subsubsection{Detection method}

The supernatant of fermentation medium was taken, and the same volume of ethyl acetate was added to extract the produced $\mathrm{AD}$, then ethyl acetate was used as solvent to dilute it 100 times to obtain the liquid to be tested. The content of $\mathrm{AD}$ in the samples was measured by the high performance liquid chromatograph (HPLC) ${ }^{[22]}$. The optimum condition was as follows: C18 column, mobile phase was methanol: water $=70: 30$, flow rate was 1 $\mathrm{mL} / \mathrm{min}$, column temperature was $30^{\circ} \mathrm{C}$, wavelength was $245 \mathrm{~nm}^{[23]}$.

Table 2. Design of response surface factors and levels

\begin{tabular}{|c|c|c|c|c|}
\hline \multirow{2}{*}{ Level } & \multicolumn{4}{|c|}{ Factor } \\
\cline { 2 - 5 } & $\boldsymbol{A}$ (Speed) /rpm & $\begin{array}{c}\boldsymbol{B} \text { (Inoculum } \\
\text { size) } / \%\end{array}$ & $\begin{array}{c}\boldsymbol{C} \text { (The ratio of the organic } \\
\text { phase) } / \%\end{array}$ & $\begin{array}{c}\boldsymbol{D} \text { (Loaded liquid) } / \\
\left(\mathbf{m L ~} \mathbf{5 0 0 m L}^{-1}\right)\end{array}$ \\
\hline-1 & 150 & 5 & 10 & 50 \\
\hline 0 & 200 & 15 & 20 & 100 \\
\hline 1 & 250 & 25 & 30 & 150 \\
\hline
\end{tabular}

\subsubsection{Yield calculation method}

AD standard solution with $\mathrm{AD}$ concentrations of 0.0001 $\mathrm{g} / \mathrm{L}, 0.001 \mathrm{~g} / \mathrm{L}, 0.01 \mathrm{~g} / \mathrm{L}, 0.1 \mathrm{~g} / \mathrm{L}$ and $1 \mathrm{~g} / \mathrm{L}$ with ethyl acetate as solvent. HPLC was performed with the above method. The standard curve regression equation for peak area of concentration and spectrum of $\mathrm{AD}$ was established to calculate the concentration of $\mathrm{AD}$ under various conditions ${ }^{[24]}$.

The calculation formula of yield is as follows:

$$
\text { Yield }=\frac{m_{p}}{m_{s}} \times \frac{\mathbf{M}_{\mathrm{s}}}{\mathbf{M}_{\mathbf{p}}} \times \mathbf{1 0 0 \%}
$$

\section{Result and analysis}

\subsection{Strain growth curve}

The growth curve of the strain is shown in Figure 2.

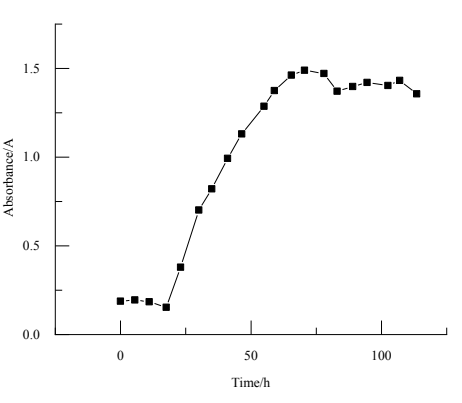

Fig. 2 Strain growth curve

Figure 2 shows that in the process of liquid culture, mycobacteria has an adaptation process when it is just inoculated into liquid medium, and some strains are difficult to adapt or even die, which is the reason why the dry weight of the cells will decrease. After about $20 \mathrm{~h}$, the strain enters the logarithmic growth phase after the lag period has elapsed. At about $70 \mathrm{~h}$, the dry weight of the strain peaked and entered a stationary phase. Therefore, it is preferred to inoculate the strain from the liquid medium to the fermentation medium at $70 \mathrm{~h}$.

\subsection{Liquid chromatography standard curve}

The standard curve for the detection of $\mathrm{AD}$ by liquid chromatography is shown in Figure 3: 


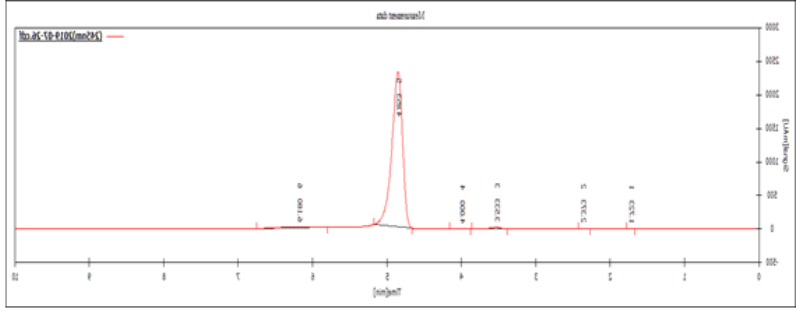

Fig. 3 HPLC curves of $0.01 \mathrm{~g} / \mathrm{L}$ androstenedione

It can be seen from Fig. 3 that under this liquid chromatography condition, the peak time of $\mathrm{AD}$ is about $4.8 \mathrm{~min}$.

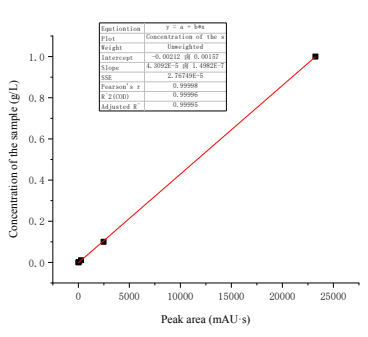

Fig 4 Liquid phase standard curve of androstenedione

Through the linear fitting in figure 4 , the standard curve regression equation of the peak area calculated by the concentration of $\mathrm{AD}$ and the spectral diagram is as follows:

$$
y=4.3092 \times 10^{-5} \chi-0.00212
$$

Where $y$ is the $\mathrm{AD}$ concentration after the sample is diluted 100 times, and $\mathrm{x}$ is the peak area of the liquid chromatography.

\subsection{Orthogonal test results}

The results of orthogonal experiment are shown in table 3

Table 3. Orthogonal test results

\begin{tabular}{|c|c|c|c|c|c|c|}
\hline Number & Temperature/ $\left({ }^{\circ} \mathrm{C}\right)$ & pH & $\begin{array}{c}\text { Substrate } \\
\text { concentration/ }(g / L)\end{array}$ & $\begin{array}{l}\text { Vegetable } \\
\text { oil kind }\end{array}$ & $\begin{array}{c}\text { AD } \\
\text { concentration / } \\
(\mathrm{g} / \mathrm{L})\end{array}$ & Yield/\% \\
\hline 1 & 30 & 8.5 & 0.8 & 3 & 3.77 & 64.26 \\
\hline 2 & 40 & 7.5 & 0.8 & 5 & 1.21 & 20.71 \\
\hline 3 & 35 & 8.0 & 0.8 & 4 & 3.63 & 61.95 \\
\hline 4 & 20 & 6.5 & 1.0 & 4 & 3.63 & 49.58 \\
\hline 5 & 20 & 8.0 & 0.8 & 2 & 3.77 & 64.30 \\
\hline 6 & 40 & 9.0 & 0.6 & 4 & 1.22 & 27.80 \\
\hline 7 & 40 & 6.5 & 0.4 & 1 & 1.97 & 67.33 \\
\hline 8 & 40 & 8.5 & 0.4 & 2 & 1.19 & 40.55 \\
\hline 9 & 30 & 7.0 & 0.8 & 4 & 4.62 & 78.70 \\
\hline 10 & 20 & 8.0 & 0.4 & 3 & 2.43 & 82.88 \\
\hline 11 & 30 & 7.5 & 0.4 & 1 & 2.34 & 79.75 \\
\hline 12 & 30 & 6.0 & 0.4 & 2 & 2.47 & 84.29 \\
\hline 13 & 35 & 7.5 & 1.0 & 2 & 1.29 & 17.54 \\
\hline 14 & 25 & 7.0 & 0.8 & 2 & 4.56 & 77.82 \\
\hline 15 & 30 & 9.0 & 0.8 & 5 & 4.28 & 72.99 \\
\hline 16 & 35 & 8.5 & 0.8 & 1 & 4.20 & 71.59 \\
\hline 17 & 25 & 6.5 & 0.8 & 2 & 4.28 & 72.97 \\
\hline 18 & 20 & 7.0 & 0.8 & 1 & 4.44 & 75.71 \\
\hline 19 & 40 & 7.0 & 1.0 & 3 & 4.35 & 59.35 \\
\hline 20 & 35 & 9.0 & 0.4 & 1 & 2.26 & 76.94 \\
\hline 21 & 20 & 9.0 & 0.8 & 2 & 3.80 & 64.85 \\
\hline 22 & 40 & 8.0 & 0.8 & 2 & 0.74 & 12.69 \\
\hline 23 & 20 & 8.5 & 0.4 & 4 & 1.29 & 44.13 \\
\hline 24 & 30 & 6.5 & 0.6 & 2 & 3.27 & 74.39 \\
\hline 25 & 25 & 6.0 & 0.8 & 4 & 4.42 & 75.36 \\
\hline 26 & 20 & 7.0 & 0.4 & 5 & 2.16 & 73.74 \\
\hline 27 & 25 & 9.0 & 0.4 & 3 & 2.36 & 80.44 \\
\hline 28 & 20 & 6.5 & 0.8 & 3 & 3.88 & 66.10 \\
\hline 29 & 35 & 6.0 & 0.6 & 3 & 1.07 & 24.24 \\
\hline 30 & 25 & 7.0 & 0.6 & 1 & 0.89 & 20.34 \\
\hline 31 & 25 & 8.5 & 0.8 & 1 & 4.38 & 74.66 \\
\hline 32 & 20 & 6.0 & 0.8 & 1 & 4.43 & 75.62 \\
\hline 33 & 20 & 7.5 & 0.8 & 1 & 4.22 & 72.04 \\
\hline 34 & 25 & 7.5 & 0.4 & 4 & 1.96 & 66.96 \\
\hline
\end{tabular}




\begin{tabular}{|l|l|l|l|l|l|l|}
\hline 35 & 25 & 6.5 & 0.4 & 1 & 2.37 & 80.90 \\
\hline 36 & 20 & 6.0 & 0.4 & 2 & 2.44 & 83.24 \\
\hline 37 & 25 & 8.5 & 1.0 & 2 & 4.22 & 57.58 \\
\hline 38 & 25 & 8.0 & 0.6 & 1 & 3.61 & 82.02 \\
\hline 39 & 20 & 7.5 & 0.6 & 2 & 3.26 & 74.10 \\
\hline 40 & 20 & 9.0 & 1.0 & 1 & 1.23 & 16.76 \\
\hline 41 & 25 & 6.0 & 1.0 & 5 & 1.35 & 18.43 \\
\hline 42 & 35 & 7.0 & 0.4 & 2 & 1.32 & 45.16 \\
\hline 43 & 25 & 7.5 & 0.8 & 3 & 3.28 & 55.94 \\
\hline 44 & 25 & 9.0 & 0.8 & 2 & 3.84 & 65.54 \\
\hline 45 & 20 & 8.5 & 0.6 & 5 & 2.07 & 47.16 \\
\hline 46 & 25 & 8.0 & 0.4 & 5 & 1.16 & 39.55 \\
\hline 47 & 35 & 6.5 & 0.8 & 5 & 4.23 & 72.17 \\
\hline 48 & 40 & 6.0 & 0.8 & 1 & 4.31 & 73.56 \\
\hline 49 & 30 & 8.0 & 1.0 & 1 & 4.38 & 59.77 \\
\hline
\end{tabular}

From the yield results in Table 3, the fermentation conditions with the highest yield were: temperature $30^{\circ} \mathrm{C}$, initial $\mathrm{pH}$ 6.0, plant sterol concentration $0.4 \mathrm{~g} / \mathrm{L}$, and water/soybean oil aqueous two-phase system under these conditions. The yield can be as high as $84.29 \%$; the fermentation power curve is shown in Figure 5:

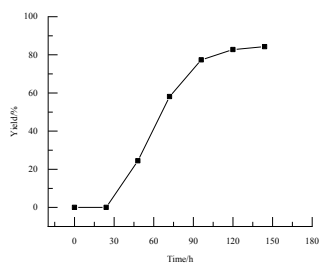

Fig 5 Concentration change chart under the highest yield fermentation conditions
As can be seen from Fig. 5, the rate of change of $\mathrm{AD}$ concentration is already low at about $144 \mathrm{~h}$ after the start of fermentation, so it is reliable to measure the fermentation conditions by using the $\mathrm{AD}$ yield at this time as the final result.

According to the above orthogonal test result table, relevant data analysis is carried out ${ }^{[25]}$, and the analysis results are shown in Table 4, Table 5 and Table 6:

Table 4. Normal test results

\begin{tabular}{|c|c|c|c|}
\hline Item & Statistic & DOF & P \\
\hline Kolmogorov-Smirnov & 0.189 & 49 & 0.064 \\
\hline Shapiro-Wilk & 0.856 & 49 & 0.102 \\
\hline
\end{tabular}

Table 5. Mean response of factors

\begin{tabular}{|c|c|c|c|c|}
\hline Level & Temperature & $\mathbf{p H}$ & Substrate concentration & Vegetable oil kind \\
\hline 1 & 63.59 & 62.32 & 67.67 & 66.21 \\
\hline 2 & 62.04 & 69.06 & 50.01 & 59.75 \\
\hline 3 & 73.66 & 61.54 & 65.22 & 61.89 \\
\hline 4 & 52.80 & 55.29 & 39.86 & 57.78 \\
\hline 5 & 43.14 & 57.59 & & 49.25 \\
\hline 6 & & 57.13 & & 16.96 \\
\hline 7 & & 57.9 & & 3 \\
\hline Delta & 1 & 13.77 & 27.81 & 2 \\
\hline
\end{tabular}

Table 6. Analysis of variance of factors

\begin{tabular}{|c|c|c|c|c|c|}
\hline Variable & DEVSQ & DOF & MS & F & P \\
\hline Temperature & 3896.2 & 4 & 974.1 & 2.84 & 0.041 \\
\hline $\mathrm{pH}$ & 844.7 & 6 & 140.8 & 0.41 & 0.868 \\
\hline Substrate concentration & 4932.6 & 3 & 1558.1 & 4.52 & 0.010 \\
\hline Vegetable oil kind & 1408.8 & 4 & 352.2 & 1.02 & 0.411 \\
\hline
\end{tabular}

As can be seen from Table 4, the significant level $\mathrm{P}=0.064>0.05$, and the distribution of the yield is close to the normal distribution, with statistical significance. As can be seen from Table 5, the effect of temperature on the final yield is the greatest among the four different influencing factors, the substrate concentration is second, 
the vegetable oil species is again, and the initial $\mathrm{pH}$ has the least effect on the final yield. This may be because mycobacteria $B D-696$ is sensitive to temperature conditions, and slightly higher temperatures may reduce or even inactivate its activity. But the $\mathrm{pH}$ is not static throughout the fermentation process, the strain can adapt to changes in $\mathrm{pH}$ conditions during this process.

Comparing the mean response of each factor with respect to yield, the fermentation conditions with the highest $\mathrm{AD}$ yield were estimated to be $30^{\circ} \mathrm{C}$, initial $\mathrm{pH}$ 6.5 , plant sterol concentration $0.4 \mathrm{~g} / \mathrm{L}$, and water/sweet oil dual aqueous phase system.

The analysis results show that the concentration of sterol as a substrate is not positively related to the yield, conversely, the yield is rather low when the substrate concentration is high. This indicates that mycobacteria cannot fully utilize and decompose all plant sterols when the substrate is at a high concentration. The unutilized plant sterols inhibited biochemical reactions which is mycobacteria produce AD.

\subsection{Response surface test results}

The response surface test results and correlation analysis are shown in the following table:

Table 7. Response surface test results

\begin{tabular}{|c|c|c|c|c|c|}
\hline Number & $\begin{array}{c}\text { A }(\text { Speed }) / \\
\text { rpm }\end{array}$ & B (Inoculum size) $/$ & $\begin{array}{c}\text { C (The ratio of the } \\
\text { organic phase) } \\
/ \% \\
\end{array}$ & $\begin{array}{c}\text { D (Loaded liquid) / } \\
\left(\mathrm{mL} \cdot 500 \mathrm{~mL}^{-1}\right)\end{array}$ & $\begin{array}{l}\text { Yield/ } \\
(\%)\end{array}$ \\
\hline 1 & 200 & 15 & 30 & 150 & $69.13 \%$ \\
\hline 2 & 150 & 15 & 30 & 100 & $39.00 \%$ \\
\hline 3 & 200 & 15 & 20 & 100 & $66.86 \%$ \\
\hline 4 & 200 & 5 & 10 & 100 & $48.74 \%$ \\
\hline 5 & 200 & 25 & 10 & 100 & $51.38 \%$ \\
\hline 6 & 150 & 15 & 10 & 100 & $37.27 \%$ \\
\hline 7 & 150 & 5 & 20 & 100 & $22.99 \%$ \\
\hline 8 & 200 & 15 & 30 & 50 & $64.34 \%$ \\
\hline 9 & 250 & 15 & 20 & 50 & $84.23 \%$ \\
\hline 10 & 200 & 15 & 20 & 100 & $73.25 \%$ \\
\hline 11 & 250 & 25 & 20 & 100 & $68.79 \%$ \\
\hline 12 & 200 & 5 & 20 & 150 & $50.76 \%$ \\
\hline 13 & 250 & 15 & 10 & 100 & $82.62 \%$ \\
\hline 14 & 150 & 15 & 20 & 50 & $45.05 \%$ \\
\hline 15 & 200 & 25 & 30 & 100 & $53.19 \%$ \\
\hline 16 & 200 & 15 & 10 & 50 & $59.60 \%$ \\
\hline 17 & 250 & 15 & 30 & 100 & $83.43 \%$ \\
\hline 18 & 200 & 25 & 20 & 150 & $55.50 \%$ \\
\hline 19 & 200 & 5 & 30 & 100 & $49.11 \%$ \\
\hline 20 & 200 & 25 & 20 & 50 & $56.25 \%$ \\
\hline 21 & 200 & 15 & 20 & 100 & $69.13 \%$ \\
\hline 22 & 200 & 15 & 20 & 100 & $68.60 \%$ \\
\hline 23 & 150 & 25 & 20 & 100 & $25.72 \%$ \\
\hline 24 & 250 & 15 & 20 & 150 & $85.77 \%$ \\
\hline 25 & 200 & 15 & 10 & 150 & $65.55 \%$ \\
\hline 26 & 200 & 5 & 20 & 50 & $50.35 \%$ \\
\hline 27 & 250 & 5 & 20 & 100 & $72.70 \%$ \\
\hline 28 & 200 & 15 & 20 & 100 & $70.73 \%$ \\
\hline 29 & 150 & 15 & 20 & 150 & $48.00 \%$ \\
\hline
\end{tabular}

Table 8. Response surface test anova table

\begin{tabular}{|c|c|c|c|c|c|}
\hline Sources of variance & SS & DOF & MS & F & P \\
\hline Model & 0.75 & 14 & 0.054 & 64.79 & $<0.0001$ \\
\hline A & 0.56 & 1 & 0.56 & 679.25 & $<0.0001$ \\
\hline
\end{tabular}




\begin{tabular}{|c|c|c|c|c|c|}
\hline B & $2.179 \mathrm{E}-003$ & 1 & $2.179 \mathrm{E}-003$ & 2.64 & 0.1267 \\
\hline $\mathrm{C}$ & $1.420 \mathrm{E}-003$ & 1 & $1.420 \mathrm{E}-003$ & 1.72 & 0.2110 \\
\hline $\mathrm{D}$ & $1.852 \mathrm{E}-003$ & 1 & $1.852 \mathrm{E}-003$ & 2.24 & 0.1566 \\
\hline $\mathrm{AB}$ & $1.102 \mathrm{E}-003$ & 1 & $1.102 \mathrm{E}-003$ & 1.33 & 0.2674 \\
\hline $\mathrm{AC}$ & $2.147 \mathrm{E}-005$ & 1 & $2.147 \mathrm{E}-005$ & 0.026 & 0.8742 \\
\hline $\mathrm{AD}$ & 4.919E-005 & 1 & 4.919E-005 & 0.060 & 0.8108 \\
\hline $\mathrm{BC}$ & $5.208 \mathrm{E}-005$ & 1 & $5.208 \mathrm{E}-005$ & 0.063 & 0.8054 \\
\hline $\mathrm{BD}$ & $3.298 \mathrm{E}-005$ & 1 & $3.298 \mathrm{E}-005$ & 0.040 & 0.8445 \\
\hline $\mathrm{CD}$ & $3.388 \mathrm{E}-005$ & 1 & $3.388 \mathrm{E}-005$ & 0.041 & 0.8425 \\
\hline $\mathrm{A}^{2}$ & 0.016 & 1 & 0.016 & 19.40 & 0.0006 \\
\hline $\mathrm{B}^{2}$ & 0.17 & 1 & 0.17 & 206.80 & $<0.0001$ \\
\hline $\mathrm{C}^{2}$ & 0.010 & 1 & 0.010 & 12.55 & 0.0033 \\
\hline $\mathrm{D}^{2}$ & 6.819E-006 & 1 & 6.819E-006 & $8.253 \mathrm{E}-003$ & 0.9289 \\
\hline Residual & 0.012 & 14 & $8.263 \mathrm{E}-004$ & & \\
\hline Lack of fit & $9.246 \mathrm{E}-003$ & 10 & $9.246 \mathrm{E}-004$ & 1.59 & 0.3465 \\
\hline Pure error & $2.322 \mathrm{E}-003$ & 4 & $5.806 \mathrm{E}-004$ & & \\
\hline Overall error & 0.76 & 28 & & & \\
\hline
\end{tabular}

According to the results of the response surface test and the variance analysis, the regression model $\mathrm{P}<0.0001$, the model is significant; the missing term $\mathrm{P}=0.3465$, which is not significant. The coefficient of determination is 0.9848 , which indicates that the model has a high degree of fitting. In addition, the primary term $\mathrm{A}$, the secondary terms $\mathrm{A}^{2}, \mathrm{~B}^{2}$, and $\mathrm{C}^{2}$ have a significant effect on the yield $(\mathrm{P}<0.0001)$. B, C and D had no significant effect on the yield of AD produced by Mycobacterium BD-696 within the range of parameters obtained by the experiment $(\mathrm{P}>0.05)$. Through optimization analysis, the quadratic multiple regression model equation calculated by actual factors is:

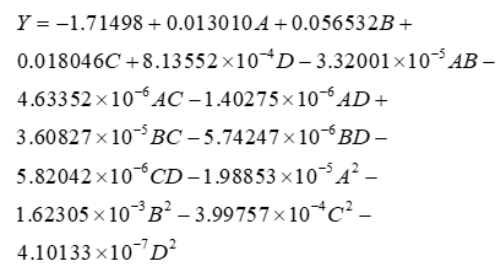

The contour map and response surface 3D map are shown in Figure 6-11.

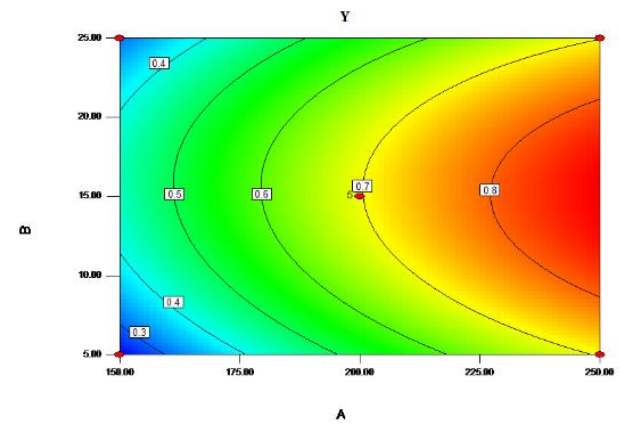

a Contour plot of $\mathrm{AB}$

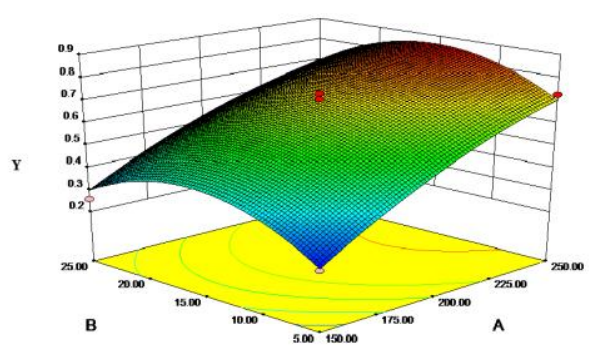

b Surface of response for $\mathrm{AB}$

Fig. 6. Interaction diagram of rotation speed and inoculation amount on $\mathrm{AD}$ yield

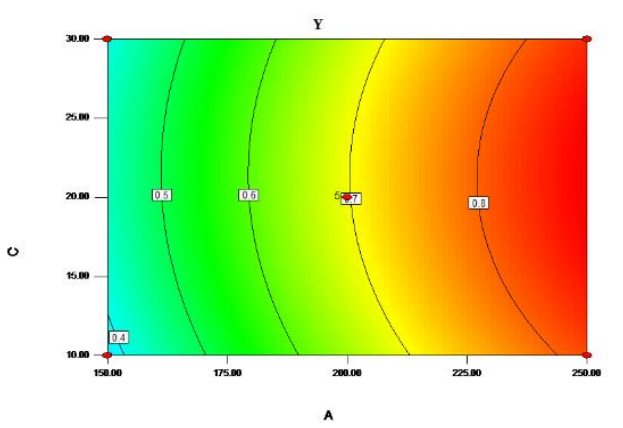

a Contour plot of AC 


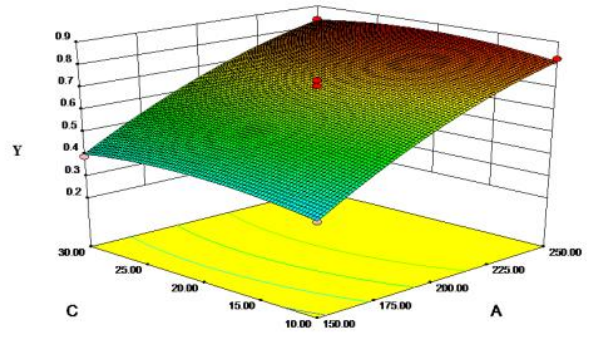

b Surface of response for AC

Fig. 7. Interaction diagram of rotation speed and organic ratio on $\mathrm{AD}$ yield
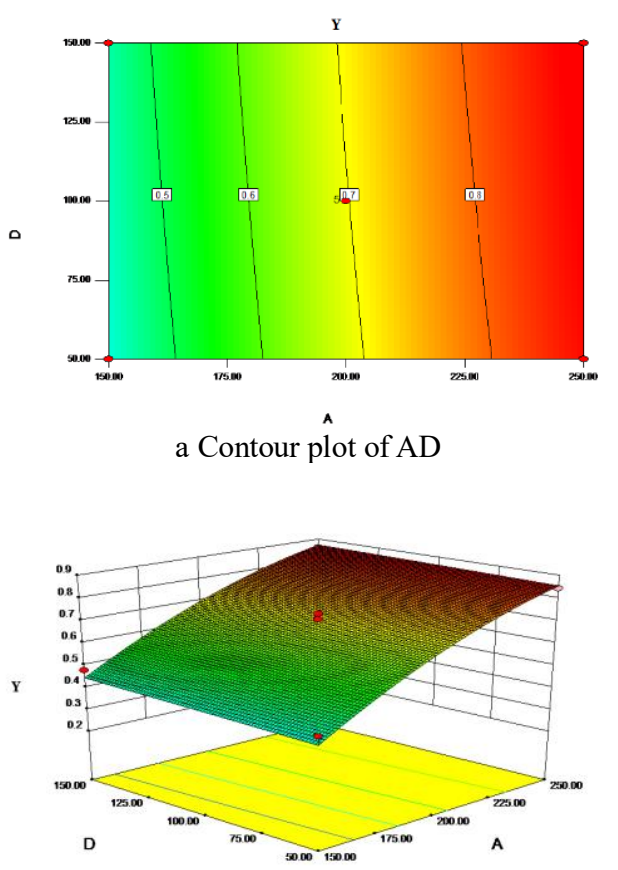

b Surface of response for AD

Fig. 8. Contour and interaction diagrams of response surface analysis

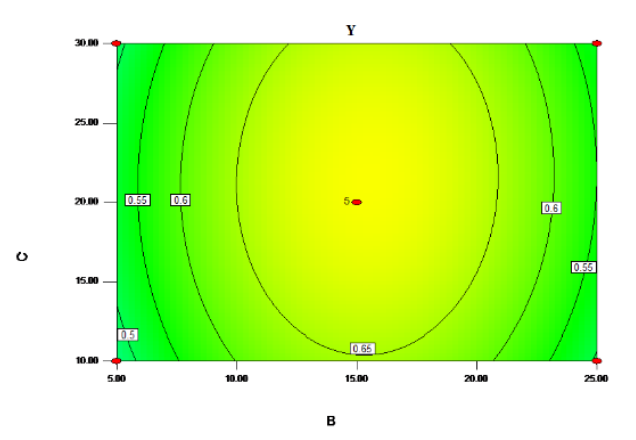

a Contour plot of $\mathrm{BC}$

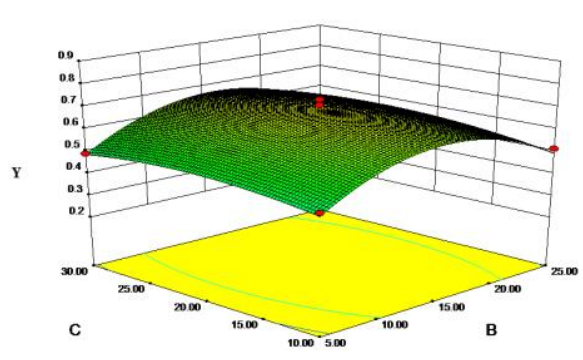

b Surface of response for $\mathrm{BC}$

Fig. 9. Interaction diagram of rotation speed and loading volume on $\mathrm{AD}$ yield

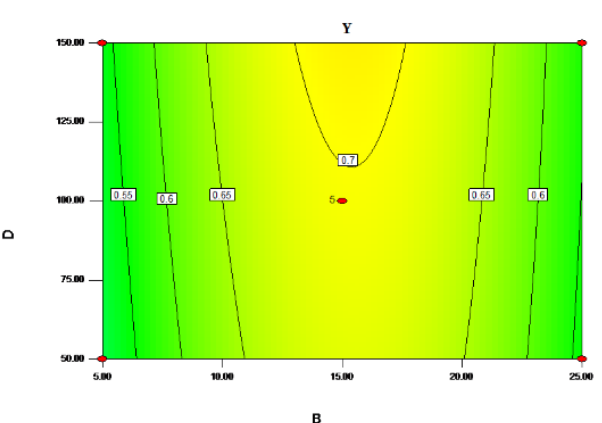

a Contour plot of $\mathrm{BD}$

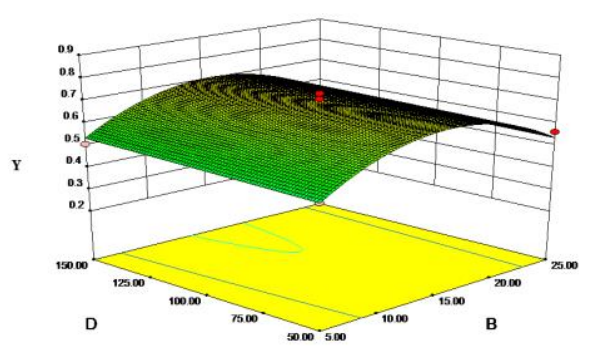

b Surface of response for BD

Fig. 10. Interaction diagram of inoculation volume and loading volume on $\mathrm{AD}$ yield

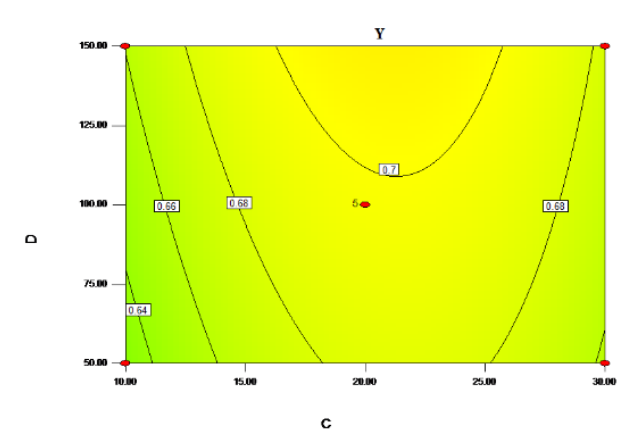

a Contour plot of CD 


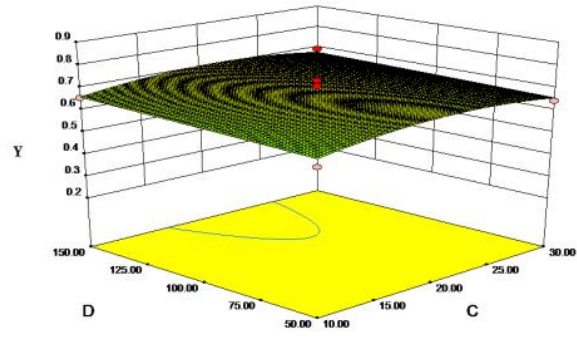

b Surface of response for CD

Fig. 11. Interaction diagram of organic phase ratio and loading volume on $\mathrm{AD}$ yield

As can be seen from the figure, the higher the rotational speed, the higher the yield of AD. At higher rotational speeds, the microorganisms and the substrate are in full contact, and the product can be evenly distributed to the entire fermentation environment in time. Presumably that's why it doesn't affect the forward direction of the reaction. In the case of a higher inoculum, the yield of AD did not increase as it increased. Probably because when the inoculum is too large, the adequate growth of mycobacteria is hampered by insufficient nutrients, this affects its biological function of using the substrate to produce AD.

Less inoculation resulted in insufficient activity of the whole fermentation system, and of course, the yield of AD was low.

On the other hand, the yield can reach a higher value when the ratio of the organic phase to the liquid loading is moderate. The order of influence of each variable on the yield of $A D$ is $A>B>D>C$. The yield of $A D$ has a maximum at a relatively suitable rotational speed and inoculum size, and the rotational speed is higher at this time, while the inoculum amount, liquid volume, and organic ratio are moderate.

After optimization of the response surface, the optimal process conditions for the production of $\mathrm{AD}$ by the obtained microbial method are A (rotation speed) $=250$ $\mathrm{rpm}, \mathrm{B}$ (inoculation amount) $=14.83 \%, \mathrm{C}$ (organic ratio) $=20.65 \%$, D (loading amount $)=150 / 500 \mathrm{~mL}$. The yield of $\mathrm{AD}$ under this optimal fermentation condition was predicted to be $87.18 \%$.

When the optimization parameters are corrected in the results of the verification response surface analysis, they are: $\mathrm{A}$ (rotation speed) $=250 \mathrm{rpm}, \mathrm{B}$ (inoculation amount) $=15 \%, \mathrm{C}($ organic ratio $)=21 \%, \mathrm{D}($ loading amount $)=150$ $1500 \mathrm{~mL}$. Under these conditions, three trials were carried out to verify that the AD yields were $86.23 \%, 85.84 \%$, and $84.96 \%$, respectively, and the relative errors were $1.09 \%$, $1.54 \%$, and $2.55 \%$, respectively, compared with the predicted values. Therefore, the model can predict the effect of rotational speed, inoculum size, organic phase ratio and liquid loading on $\mathrm{AD}$ yield under this fermentation condition.

\section{Conclusions}

The highest yield fermentation conditions in orthogonal experiments were: temperature $30^{\circ} \mathrm{C}$, initial $\mathrm{pH} 6.0$, plant sterol concentration $0.4 \mathrm{~g} / \mathrm{L}$, and water/soybean oil aqueous two-phase system. The yield under this condition can be as high as $84.29 \%$.

The order of influence of different environmental influence factors on the final yield is: temperature $>$ substrate concentration $>$ vegetable oil type $>$ initial $\mathrm{pH}$. The optimal conditions for the production of AD by mycobacteria BD-696 in the two-phase system are: temperature $30{ }^{\circ} \mathrm{C}$, initial $\mathrm{pH} 6.5$, plant sterol concentration $0.4 \mathrm{~g} / \mathrm{L}$, water/sweet oil dual aqueous phase system.

On the basis of the orthogonal experimental results, the fermentation conditions with the highest yield in the actual experiment of response surface were: rotation speed 250 rpm, inoculum volume $15 \%$, organic comparison example $20 \%$, liquid loading $150 / 500 \mathrm{~mL}$. The yield under this condition can be as high as $85.77 \%$. The order of influence of each variable on the yield of $\mathrm{AD}$ was speed $>$ inoculum $>$ liquid volume $>$ organic phase. The optimal fermentation conditions for the effective prediction of the response surface model are: speed of $250 \mathrm{rpm}$, inoculum size of $14.83 \%$, organic ratio of $20.65 \%$, and liquid loading of $150 / 500 \mathrm{~mL}$. At this time, the yield of AD can be as high as $87.18 \%$.

\section{References}

1. RX Guo, LG Li, YF Wang, et al. Historical story on natural medicinal chemistry: Steroids[J]. Chin. Tradit. Herb. Drugs, 2016, 47(8): 1251-1264 (in Chinese)

2. HLJ Makin, JW Honour, CHL Shackleton, et al. General Methods for the extraction, purification, and measurement of steroids by chromatography and mass spectrometry[M]. Dordrecht: Springer, 2010: 163-282

3. None. Abstracts from the 2017 society of general internal medicine annual meeting[J]. J. Gen. Inter Med, 2017, 32(2): 83-808

4. YL Yin. Effects of different carbon sources on growth, membrane permeability, $\beta$-sitosterol consumption, androstadienedione and androstenedione production by Mycobacterium Neoaurum $[\mathrm{J}]$. Interdiscip. Sci.: Comput. Life Sci, 2016, 8(1): 102-107

5. K Wu. Studies on the technology of enzymatic production of cholest-4-en-3- one in aqueous/organic biphasic system[D]. Chengdu: Master's Thesis of Sichuan Normal University, 2009 (in Chinese)

6. P Ye, B Yang, XH Guo, et al. Synthesis of 5ß-androst3-en-17-one[J]. Cent. South Pharm., 2016, 14(9): 957-959 (in Chinese)

7. J Wang. Fermentation of Immobilized Mycobacterium sp. BD 696-6 for production of androst- 4-ene- 3,17- dine from rapeseed sterols[J]. Food Sci 2012, 2012(11): 216-222(in Chinese)

8. JC Stark, SL Love, BA King. et al. Potato cultivar response to seasonal drought patterns[J]. Am. J. Potato Res, 2013, 90(3): 207-216 
9. SX Feng. Study on the introduction of specific sidechains at $\mathrm{C} 17$ position of androstene dione and synthesis of the steroidal drugs[D]. [Zhengzhou]: Doctoral Dissertation of Zhengzhou University, 2015 (in Chinese)

10. W Han, YX Li, M Yang, et al. Effects、sources and behaviors of environmental androgens[J]. Acta Ecol. Sin, 2010, 30(6): 1594-1603 (in Chinese)

11. RA Mancilla, R Pavezdíaz, A Amoroso. Production and biotransformation of phytosterol microdispersions to produce 4-androstene-3,17dione.[J]. Micr. Ster, 2017, 1645(7): 159-165

12. KD Josefsen, A Nordborg, H Sletta. Bioconversion of phytosterols into androstenedione By Mycobacterium[J]. Micr. Ster, 2017, 1645(7): 177197

13. SZ Xiong. The utilization of the broth of microorganism transform theintermediate of phytosterols drugs[D]. Wuhan: Master's Thesis of Wuhan Polytechnic University, 2014 (in Chinese)

14. M Rousková, A Heyberger, J Tříska, et al. Extraction of phytosterols from tall oil soap using selected organic solvents[J]. Chem. Pap, 2011, 65(6): 805812

15. YG Xu, YX Guan, H Wang. Microbial side-chain cleavage of phytosterols bymycobacteriain vegetable oil/aqueous two-phase system[J]. Appl. Biochem. Biotechnol, 2014, 174(2): 522-533

16. $\mathrm{XW} \mathrm{Xu,} \mathrm{X} \mathrm{Gao,} \mathrm{J} \mathrm{Feng,} \mathrm{et} \mathrm{al.} \mathrm{Influence} \mathrm{of}$ temperature on nucleus degradation of 4-androstene3, 17-dione in phytosterol biotransformation by Mycobacterium sp.[J]. Lett. Appl. Microbiol, 2015, 61(1): 63-68

17. ST Jiang, JP Zhao, Y Yang, et al. The wildlife conservation foundation regularly visits panda
reserves[J] Food Ferment. Ind, 2008, 34(6):46-48(in Chinese)

18. LJ Huang, HB Zhang, XQ Hu, et al.Study on breeding and fermentation conditions of a high androstenedione-producing mutant[J]. J. Biol, 2013, 30(4):54-57.

19. KC Wang. Study on isolation and culture of mycobacterium by AGAR solid medium[J]. Int. J. Lab. Med, 2017, 2017(A01): 128-129 (in Chinese)

20. XX Li, Z Wen, KS Xiao, et al. Effect of BCyclodextrin on the gGrowing characteristic of steroid-biotransformation microorganism $[\mathrm{J}]$. J. Tianjin Univ. Sci. Technol, 2006, 21(3): 1-4 (in Chinese)

21. K Xue, R Wang, YF Wang, et al. Optimization of $9 \alpha-$ Hydroxyandrostenedione preparation from phytosterols transformation by response surface methodology[J]. Food Ind, 2017, 2017(9): 169-173. (in Chinese)

22. V Gulla, T Banerjee, S Patil. Quantitative TLC analysis of steroid drug intermediates formed during bioconversion of soysterols $[\mathrm{J}]$. Chromatographia, 2008, 68(7): 663-667

23. LJ Pan, BH Luo, ST Jiang, et al. Study on extraction of androst-4-diene-17-dione from oil-water twophase fermentation system of mycobacterium B696[J]. Food Sci, 2009, 30(11): 144-146 (in Chinese)

24. Y Yang, ST Jiang, LJ Pan, et al. Study on Biotransformation of AD from Phytosterol in TwoPhase Systems[J]. Food Ferment. Ind, 2008,34(9): 61-64

25. FS Zhang, SX Guo. Application of SPSS orthogonal design in tissue culture of Fujian Golden Lotus[J]. China J. Chin. Mater. Med, 2009, 34(20): 2581-2585 (in Chinese) 